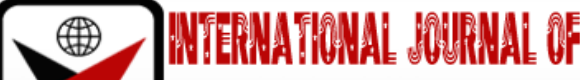

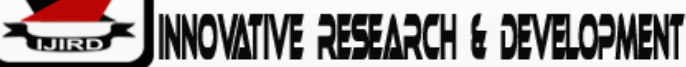

ISSN 2278-0211 (Online)

\section{Constructing a Financial Conditions Index for Emerging and Developing Countries: A Static Panel Data Approach}

\author{
Okereke Emeka, J. \\ Professor, Department of Finance and Banking, \\ University of Port Harcourt, Choba, Nigeria \\ Theophilus Boufini \\ Doctoral Student, Department of Finance and Banking, \\ University of Port Harcourt, Choba, Nigeria
}

\begin{abstract}
:
This study employs the basic panel data framework to develop a financial conditions index for six emerging and developing countries and estimate its impact on both economic growth and inflationary trend. The countries are Brazil, Malaysia, Mexico, Nigeria, Pakistan and South Africa, while the selected financial variables are treasury bills rate, real effective interest rate, interest rate spread, credit to private sector ratio to nominal GDP and market capitalization ratio to nominal GDP. Using annual data from 2010 to 2010, our findings indicate that real effective exchange rate is the most significant variable in the constructed financial conditions index, followed by credit to private sector, while treasury bills rate, interest rate spread and market capitalization play an insignificant role in the index. Our evidence also indicates that the constructed financial conditions index has a highly significant explanatory power for economic growth, while it contains little information for future inflationary trend. We, therefore, argue that adopting policies that focuses more on exchange rate and financial deepening would accelerate economic growth process in emerging and developing countries.
\end{abstract}

Keywords: Financial conditions index, economic growth, inflation

\section{Introduction}

The significance of monetary policy in economic performance and growth process is well recognized by both policymakers and researchers. However, the effectiveness of monetary policy depends largely on the appropriateness of the intermediate variables chosen to convey the policy shocks to the real economy. The importance of intermediate variables in the monetary policy formulation and implementation process stems from the indirect relationship that exists between monetary policy and real economic indicators. Traditionally, monetary authorities rely on interest rate and exchange rate as intermediate variables for monetary policy effectiveness. However, while these intermediate variables are generally believed to play a significant role in the monetary policy transmission process, there is, however, growing concern regarding whether their effects (both individually and jointly) are sufficient to achieve the desired policy objectives.

There are also documented instances when both interest rate and exchange rate play only a negligible role in the monetary policy transmission mechanism, especially during the recent global financial crisis (Aramonte, Rosen \& Schindler, 2017). Hence, scholars have been developing more robust channels for monetary policy effectiveness. The financial conditions index (FCI) seems to be among the recommended innovations that promise to effectively bridge the gap between monetary policy shocks and the real economy. Compared with the traditional channels, the FCI is a comprehensive index encompassing both monetary policy indicators (interest rate and exchange rate) and current financial market conditions indicators (equity prices and house prices), usually weighted based on an economic model (Gauthier, Graham\& Liu, 2004). Hence, it is believed to provide a more accurate forecast of future economic trend and performance (Ejem \& Ogbonna, 2020; Ogbonna \& Ejem, 2020).

However, while the significance of the FCI has theoretical underpinning, there is a large body of empirical evidence suggesting that financial conditions indicators, not only have a direct relationship with real economic variables, but also have a strong correlation with monetary variables. In short, empirical evidence reported by several studies suggests that FCI performs better than the previously used monetary conditions index or MCI (weighted average of interest rate and exchange rate) in predicting the future growth and inflationary trend. Hence, omitting these important explanatory factors for macroeconomic performance would, no doubt, lead to inaccurate forecast of the future trend in real variables such as economic growth and inflation.

Although, FCI has attracted a considerable scholarly attention since its first appearance in the literature in the early 2000s, there is however, little agreement on how it is constructed, especially in terms of how weights are assigned to 
each component of the index. Previous studies can be grouped into three strands. The first strand of literature contains studies that follow the principal component analysis (PCA) or factor analysis approach to determine the weights of the individual components in the FCI. The second strand of literature comprises studies that construct the FCI using the dynamic VAR-based (vector autoregressive framework) impulse response functions, while the third strand comprises studies that adopt aggregate demand models or IS curve analysis.

This study contributes to the growing empirical literature by developing a financial conditions index (FCI) for six emerging and developing countries (Brazil, Malaysia, Mexico, Nigeria, Pakistan and South Africa), and examining whether the constructed FCI can predict future inflation and output using annual data from 2010 to 2019. The weight assigned to each component of the FCI corresponds to its relative contemporaneous impact on output estimated using the basic panel data model. To our knowledge, this method of estimating the weights is novel in emerging and developing countries.

The remaining part of this study is organized as follows. The next section provides the literature review on financial conditions index and the effect of financial shocks on the economy. Section 3 discusses the methodology or empirical strategy. Section 4 provides the empirical results and the study is summarized and concluded in section 5.

\section{Literature Review}

Goodhart and Hofmann (2001) develop a financial conditions index for the G7 countries (Japan, US, Italy, Germany, UK, France, and Canada) using the VAR impulse response function. Based on quarterly data spanning from 1973Q1 to 1998Q4, they find that the relative impact of asset prices (house and equity prices) on output is substantial, while the constructed index are useful predictors of future inflationary trend.

Gauthier, Graham and Liu (2004) employ three approaches: IS-curve framework, generalized IRF (impulse response functions), and factor analysis, to develop three financial conditions indexes for Canada. The sample comprises monthly time-series observations for twenty years from 1981 to 2000 . The three constructed FCIs are evaluated based on five performance criteria: consistency with economic theory, predictive power for business cycle turning points, dynamic correlation with output, in-sample explanatory power for output, and out-of-sample forecasting performance. They find that the FCIs perform much better than the existing monetary conditions index used by the Bank of Canada. Also, their results show that, in general, equity prices, housing prices, bond yield risk premiums, exchange rates, short-term interest rates, and long-term rates all are significant explanatory factors for output. They also find that the FCIs outperform the Bank of Canada's MCI in many areas

Beaton, Lalonde and Luu (2009) construct two growth-based financial condition indexes (FCIs) for the United States using quarterly data from 1979Q3 to 2009Q1. The first FCI is constructed within the framework of structural VECM, while the second is estimated based on a large-scale macroeconomic model. Their results suggest amongst others that the impact of restrictive financial policies on GDP growth during the 2007-2009 financial crisis amplified by up to 40\% as result of the zero lower bound level which the policy interest rates attained.

Angelopoulou, Balfoussia and Gibson (2014) construct three variants of financial conditions index (FCI) for the euro area from 2003 to 2011 using the principal components analysis (PCA) approach. One variant incorporates the effects of monetary policy variables while the other two variants excluded the impact of monetary policy. When financial conditions in core and periphery euro countries are compared, the result shows a significant divergence both before and during financial crisis. However, this divergence becomes less evident when monetary policy impact is incorporated in the FCI. Also, monetary policy seems to have an asymmetric impact on financial conditions across the euro area.

Using a nonlinear logistic smooth transition VAR framework, Balcilar, Thompson, Gupta and Van Eyden (2016) examine whether the response of the South African economy to financial conditions shocks has both non-linear and asymmetric effects. The effect of financial conditions is evaluated based on the previously constructed FCI comprising 16 financial variables. They find that response of the economy to financial shocks is non-linear. Also, while Treasury Bills rates and manufacturing output growth are more affected by unexpected changes in financial conditions, inflation is more affected by financial conditions during recessions.

Bulut (2016) considers whether a financial conditions index constructed from six financial variables using the PCA framework can help predict inflation in Turkey using quarterly data covering the period from 2005Q1 to 2015Q3. The financial variables are real domestic credit gap, real effective exchange rate gap, real stock market index gap, real commercial lending rate, real short-term interest rate and real shadow rate. The results from causality tests show that FCI and inflation are jointly determined.

Sahoo (2017) develop a financial conditions index for India and estimate its impact on inflation and output using quarterly data from 2008Q4 to 2015Q4. However, the author takes a different estimation approach by assigning equal weights to components of the financial conditions index as well as incorporating the impact of foreign direct investment in the index. Other variables included in the index are short-term interest rate, exchange rate and housing price index. They find that the constructed financial conditions index has the ability to predict future inflationary trend.

$\mathrm{Li}$ and Zhong (2020) examine the impact on China's financial conditions index of global economic policy uncertainty shocks within the VAR framework using monthly data from 2004M01 to 2018M12. They find that global economic policy uncertainty shocks have significant spillover effects on FCI, especially during the crisis period. There is evidence that the main source of shocks to Chinese financial markets is the uncertainty stemming from China itself. However, it seems that economic policy uncertainty from US is the most significant exogenous source of Chinese financial market variability.

Ejem and Ogbonna (2020) employ both the ARDL and VAR models to examine the predictive power of financial conditions index for economic growth and inflation in Nigeria using yearly data from 1985 to 2018. The constructed FCI comprises Treasury Bills rate, exchange rate, stock market index, credit to private sector and interest rate spread. They 
find amongst others that the constructed financial conditions index has little predictive power for both economic growth and inflation.

Ogbonna and Ejem (2020) construct a financial conditions index for six countries in the sub-Saharan African region from 2009 to 2018 using the dynamic panel data approach. The countries are Ghana, Kenya, Mauritius, Namibia Nigeria and South Africa, while the variables included in the index are treasury bills rate, interest rate spread, real effective exchange rate, credit to private sector ratio to GDP and value of stocks traded. The results from the empirical analysis show that economic growth responds only to money and capital market conditions.

\section{Methodology}

\subsection{Data Description}

Our dataset consists of annual unbalanced panel of six emerging and developing countries from 2010 to 2019 . The countries are Brazil, Malaysia, Mexico, Nigeria, Pakistan and South Africa. The variables and their sources are shown in Table 1, while summary statistics are shown in Table 2. Data analysis is done is EViews 11.

\begin{tabular}{|c|c|c|c|}
\hline Variable & Symbol & Description & Source \\
\hline GDP per capita & GDPPC & $\begin{array}{l}\text { Economic growth measured by GDP } \\
\text { per capita in current US dollars }\end{array}$ & World Development Indicators \\
\hline Inflation Rate & INFL & Annual percentage change in CPI & World Development Indicators \\
\hline Treasury Bills Rate & TBR & Short-term interest rate & International Monetary Fund \\
\hline $\begin{array}{c}\text { Real Effective } \\
\text { Exchange Rate } \\
\end{array}$ & REER & $\begin{array}{c}\text { A measure of international } \\
\text { competitiveness } \\
\end{array}$ & World Development Indicators \\
\hline Interest Rate Spread & SPREAD & $\begin{array}{l}\text { Financial intermediation efficiency } \\
\text { measured by the difference between } \\
\text { lending rate and deposit rate }\end{array}$ & World Development Indicators \\
\hline $\begin{array}{c}\text { Credit to Private } \\
\text { Sector Ratio to GDP }\end{array}$ & CPSR & A measure of financial deepening. & World Development Indicators \\
\hline $\begin{array}{c}\text { Market } \\
\text { Capitalization Ratio } \\
\text { to GDP } \\
\end{array}$ & MCAPR & Stock market size & World Development Indicators \\
\hline
\end{tabular}

Table 1: Description and Source of Variables

\begin{tabular}{|c|c|c|c|c|c|}
\hline Variable & Mean & Std. Dev. & Skewness & Kurtosis & p-value (JB) \\
\hline GDPPC & 6894.56 & 3946.01 & -0.27 & 1.55 & 0.05 \\
\hline INFL & 6.07 & 3.71 & 0.98 & 3.28 & 0.01 \\
\hline TBR & 7.56 & 3.43 & 0.26 & 1.95 & 0.20 \\
\hline REER & 95.01 & 14.36 & 0.07 & 2.30 & 0.53 \\
\hline SPREAD & 8.77 & 10.47 & 1.82 & 4.85 & 0.00 \\
\hline CPSR & 62.78 & 50.76 & 0.57 & 1.72 & 0.03 \\
\hline MCAPR & 89.22 & 93.01 & 1.25 & 3.43 & 0.00 \\
\hline
\end{tabular}

Table 2: Summary Statistics

\subsection{Empirical Models and Methods}

For empirical analysis, we employ the basic panel data framework. Hence, our econometric model for estimating the relative impact of each financial conditions index on economic growth is given as follows:

$G D P P C_{i t}=\alpha+\theta_{i}+\beta_{1} T B R_{i t}+\beta_{2} R E E R_{i t}+\beta_{3} S P R E A D_{i t}+\beta_{4} C P S R_{i t}+\beta_{5} M C A P R_{i t}+\epsilon_{i t}$

Where $\alpha$ is the intercept term, $\theta_{i}$ is the heterogeneity parameter representing the unobserved country-specific characteristics, $\epsilon_{i t}$ is the disturbance term, and $\beta_{1}, \beta_{2}, \beta_{3}, \beta_{4}$ and $\beta_{5}$ are slope parameters capturing the relative impact of financial variables on economic growth. It is worth noting that the above model is static, which is employed because of the low-frequency nature of our data.

To estimate the above model, two basic panel data methods; fixed effects and random effects methods, are employed. The main difference between these methods lies in whether $\theta_{i}$ in (1) correlates with the betas or not. While the fixed effects method assumes that $\theta_{i}$ has a significant correlation with the betas, the random effects treat $\theta_{i}$ as belonging to the family of $\epsilon_{i t}$ with zero correlation with the betas. However, the Hausman specification test is usually employed to determine the most plausible method for a given dataset.

To develop the financial conditions index for the selected countries, we follow the usual approach as follows:

$F C I=\sum_{j=1}^{n} \beta_{j}\left(y_{i, t}-\bar{y}_{j}\right)$

Where FCI = financial conditions index, $\beta_{j}=$ beta (weight) associated with variable $j$ which is estimated from (1), $y_{i, t}=$ financial variable $j$ at time $t$, and $\bar{y}_{j}=$ mean of variable $j$.

To examine the impact of FCI on economic performance, we employ the following models:

$G D P P C_{i t}=\alpha+\gamma_{i}+\lambda_{1} F C I_{i t}+\lambda_{2} I N F L_{i t}+\varepsilon_{i t}$

$I N F L_{i t}=\alpha+\phi_{i}+\psi_{1} F C I_{i t}+\psi_{2} G D P P C_{i t}+\mu_{i t}$

The estimation of (3) and (4) would be based on the outcome of Hausman test for model (1). 


\section{Analysis and Results}

\subsection{FCI Components and Growth}

First, we employ both the fixed effects and random effects methods to estimate our static panel data model for economic growth incorporating the five FCI components as explanatory variables. All variables are transformed into logarithms. The results are provided in Table 3.As evident in this Table, except for the coefficient on CPSR, most of the fixed effects coefficients have signs that conflict with those of the random effects. However, the value of the Hausman statistic is quite substantial with a zero attached probability; hence we reject the null hypothesis that supports the random effects assumptions. This implies that the unobserved country-specific characteristics have a significant correlation with the selected components of the financial conditions index in our growth model. Therefore, further analysis of the specified study relationships of interest would be based on the fixed effects results.

\begin{tabular}{|c|c|c|}
\hline Variables & Fixed Effects & Random Effects \\
\hline Constant & 2.8809 & 9.5160 \\
& $(0.0085)$ & $0.0000)$ \\
\hline TBR & 0.0261 & -1.0171 \\
& $(0.6094)$ & $0.0000)$ \\
\hline REER & 0.9878 & -0.2805 \\
& $(0.0000)$ & $(0.0143)$ \\
\hline SPREAD & -0.0968 & 0.3866 \\
& $(0.2022)$ & $0.0000)$ \\
\hline CPSR & 0.2936 & 0.8227 \\
& $(0.0385)$ & $0.0000)$ \\
\hline MCAPR & 0.0682 & -0.3816 \\
& $(0.3175)$ & $0.0000)$ \\
\hline Wald & 68.245 & 3246.81 \\
& $(0.0000)$ & $0.0000)$ \\
\hline R-squared & 0.9909 & 0.6991 \\
\hline Adjusted R-squared & 0.9888 & 0.6671 \\
\hline F-statistic & 460.16 & 21.849 \\
& $(0.0000)$ & $0.0000)$ \\
\hline Hausman & - & 1354.80 \\
& & $0.0000)$ \\
\hline
\end{tabular}

Table 3: Panel Data Results; P-Values in Parenthesis

The fixed effects results show that all the estimated coefficients have signs that are consistent with economic theory, with SPREAD being the only variable with a negative coefficient. This negative sign implies that higher interest rate spread is associated with lower economic growth. Theoretically, interest rate spread is an indication of financial intermediation efficiency, and high spread implies low transaction costs, which increases investment costs and disrupts the economic growth process. However, the SPREAD beta is marginal, while its attached p-value is reasonably higher than any conventional significance level, indicating that financial intermediation plays an insignificant role in the real economy.

Although, both TBR and MCAPR enter the growth model with the expected positive signs, their coefficients, however, are inconsiderable and the attached p-values are high, hence, their effects are insignificant, both statistically and in economic sense. This can be interpreted as suggesting that both money and capital markets playa negligible role in the growth process in the developing countries. This evidence reinforces the view that financial markets in developing countries are still underdeveloped and inefficient, hence they do not play a leading role in driving economic growth and development.

The coefficients on REER and CPSR both have the expected positive signs and their p-values are lower than 0.05 , indicating that they are significant determinants of GDP per capita. This implies that real effective exchange rate and credit to private sector are important explanatory factors for the observed cross-sectional variations in GDP per capita. Hence, strengthening the domestic currency and extending more credits to the private sector can help achieve higher economic growth in developing and emerging markets. However, REER has the largest coefficient and its impact is statistically significant at less than 1\% level, while the significance of credit to private sector is observed at $5 \%$ level.

Finally, the value of the Wald statistic, which tests the joint significance of all the observed explanatory variables, is reasonably high with a zero attached p-value, indicating that the joint impact of TBR, REER, SPREAD, CPSR and MCAPR on GDPPC is highly significant. This may be interpreted as indicating strong evidence of supply-leading theory of financegrowth relationship. Therefore, we argue that although most of the components of financial conditions index are individually not significant in the growth model, the financial sector development still drives economic growth in the developing countries. However, this is only a static view which may be subject to endogeneity bias as the possible feedback effect between FCI components and growth is not captured in our model. 


\subsection{Financial Condition Index and Its Impact on Economic Performance}

Figure 3 shows the constructed financial conditions index for the selected emerging markets and developing countries. Here, the relative weights correspond to the contemporaneous impact of each financial variable on economic growth. Hence, the index has no dynamic content as it reflects only the current developments in the financial markets. Table 4 reports the fixed effects coefficients for the effect of the FCI on economic growth and inflation.

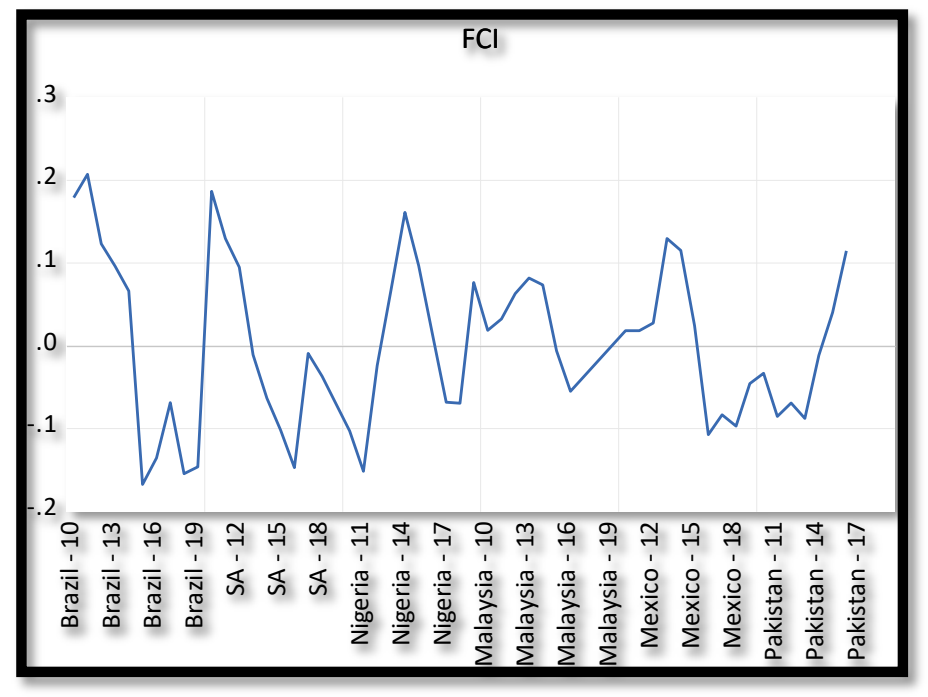

Figure 1

\begin{tabular}{|c|c|c|}
\hline Variable & GDPPC & INFL \\
\hline Constant & 8.6708 & 6.9123 \\
& $(0.0000)$ & $(0.1693)$ \\
\hline FCI & 0.9695 & -0.1593 \\
& $(0.0000)$ & $0.8285)$ \\
\hline INFL & -0.0398 & - \\
\hline GDPPC & $0.2961)$ & -0.6080 \\
& - & $0.2961)$ \\
\hline R-squared & 0.9911 & 0.7450 \\
\hline Adjusted R-squared & 0.9898 & 0.7054 \\
\hline F-statistic & 721.98 & 18.787 \\
& $(0.0000)$ & $0.0000)$ \\
\hline
\end{tabular}

Table 4: Effect of FCI on GDPPC and INFL; P-Values in Parenthesis

As Table 4 shows, the constructed FCI has the expected sign for both performance models, having a positive coefficient in the growth model, and a negative coefficient in the inflation model. This suggests that improving the conditions in the financial sector would lead to higher economic growth and also reduce inflationary pressure. However, the p-values indicate that while the impact of the estimated FCI on economic growth is highly significant, its impact on inflation is not significant even at $10 \%$ level. This implies that the constructed FCI can accurately predict future economic growth but contain little information for future inflation. This finding contradicts Goodhart and Hofmann (2001), Bulut (2016), Sahoo (2017) and Ejem and Ogbonna (2020), but tends to agree with Beaton, Lalonde and Luu (2009).

\section{Summary and Conclusions}

This study employs the basic panel data framework to develop a financial conditions index for six emerging and developing countries and estimate its impact on both economic growth and inflationary trend. The empirical analysis is based on annual data spanning from 2010 to 2019, while the variables included in the index are treasury bills rate, real effective interest rate, interest rate spread, credit to private sector ratio to nominal GDP and market capitalization ratio to nominal GDP.

The constructed FCI derived its weights from an aggregate demand model using the individual coefficients on the incorporated financial variables estimated within the fixed effects modelling framework. We find that real effective exchange rate is the most significant variable in the constructed financial conditions index, followed by credit to private sector, while treasury bills rate, interest rate spread and market capitalization play an insignificant role in the index.

We also find that the constructed financial conditions index has a highly significant explanatory power for economic growth, while it contains little information for future inflationary trend. Based on these findings, we conclude that adopting policies that focuses more on exchange rate and financial deepening would accelerate economic growth process in emerging and developing countries. 


\section{References}

i. Angelopoulou, E., Balfoussia, H., \& Gibson, H. D. (2014). Building a financial conditions index for the euro area and selected euro area countries: what does it tell us about the crisis? Economic Modelling, 38, 392-403.

ii. Ejem, C. A., \& Ogbonna, U. G. (2020). Financial conditions index and economic performance in Nigeria. American Finance \& Banking Review, 5(1), 62-70.

iii. Balcilar, M., Thompson, K., Gupta, R., \& Van Eyden, R. (2016). Testing the asymmetric effects of financial conditions in South Africa: A nonlinear vector autoregression approach. Journal of International Financial Markets, Institutions and Money, 43, 30-43.

iv. Beaton, K., Lalonde, R., \& Luu, C. (2009). A financial conditions index for the United States

v. (No. 2009-11). Bank of Canada.

vi. Bulut, U. (2016). Do financial conditions have a predictive power on inflation in Turkey? International Journal of Economics and Financial Issues, 6(2), 621 - 628.

vii. Gauthier, C., Graham, C., \& Liu, Y. (2004). Financial conditions indexes for Canada (No.2004-22). Bank of Canada.

viii. Goodhart, C., \& Hofmann, B. (2001, March). Asset prices, financial conditions, and the transmission of monetary policy. In conference on Asset Prices, Exchange Rates, and Monetary Policy, Stanford University (pp. 2-3).

ix. Li, Z., \& Zhong, J. (2020). Impact of economic policy uncertainty shocks on China's financial conditions. Finance Research Letters, 35, 101303.

x. Ogbonna, U. G. \& Ejem, C. A. (2020). Economic performance and financial conditions index nexus: Evidence from selected sub-Saharan African countries. Journal of Finance and Accounting, 8(3), 158.

xi. Sahoo, M. (2017). Financial conditions index (FCI), inflation and growth: Some evidence. Theoretical and Applied Economics, 24(3 (612), Autumn), 147-172. 